Hans-Hermann Hartwich

Göttrik Wewer (Hrsg.)

\title{
Regieren \\ in der Bundesrepublik III
}

Systemsteuerung und „Staatskunst“

Theoretische Konzepte und empirische Befunde

Beiträge von

Hans Herbert von Arnim, Wolfgang Bergsdorf,

Klaus von Beyme, Carl Böhret

Roland Czada, Hans-Hermann Hartwich

Otfried Jarren, Dirk Käsler

Klaus König, Christine Landfried

Axel Murswieck, Franz Traxler

Hajo Weber, Helmut Willke

Springer Fachmedien Wiesbaden GmbH 1991 
Die meisten der hier versammelten Beiträge konnten auf dem 3. interdisziplinären Symposium „Regieren in Parteienstaat und Interessenpluralismus “ vom 29. November bis 1 . Dezember 1990 diskutiert werden.

Die Teilnehmerinnen und Teilnehmer genossen dabei die Gastfreundschaft der Werner Reimers Stiftung in Bad Homburg.

ISBN 978-3-8100-0949-4

ISBN 978-3-663-07664-3 (eBook)

DOI 10.1007/978-3-663-07664-3

(C) 1991 by Springer Fachmedien Wiesbaden

Ursprünglich erschienen bei Leske Verlag + Budrich GmbH, Opladen 1991

Das Werk einschließlich aller seiner Teile ist urheberrechtlich geschützt. Jede Verwertung außerhalb der engen Grenzen des Urheberrechtsgesetzes ist ohne Zustimmung des Verlags unzulässig und strafbar. Das gilt insbesondere für Vervielfältigungen, Übersetzungen, Mikroverfilmungen und die Einspeicherung und Verarbeitung in elektronischen Systemen. 


\section{Inhalt}

Hans-Hermann Hartwich, Regierungslehre als System- und Handlungsanalyse

I. Regieren in handlungs- und systemtheoretischer Perspektive

Klaus von Beyme, Regierungslehre zwischen Handlungstheorie und

Systemansatz

Helmut Willke, Regieren als die Kunst systemischer Intervention

II. Regierungshandeln unter den Bedingungen des modernen

Parteien-, Verbände- und Medienstaates

Wolfgang Bergsdorf, Probleme der Regierungskommunikation

Carl Böhret, Politische Vorgaben für ziel- und ergebnisorientiertes

Verwaltungshandeln aus Regierungserklärungen?

Klaus König, Parteienstaat, Parteifunktionen, Parteipolitik

und Regierung

III. Die Bedeutung des Parteienstaates für den modernen

Regierungsprozeß ............................................ 97

Hans Herbert von Arnim, Der Parteienstaat ........................ 99

Axel Murswieck, Die Notwendigkeit der Parteien für die funktionelle Integration der Regierungsgeschäfte

IV. Regieren durch Verbände - Regieren mittels der Verbände

Franz Traxler, Regieren die Verbände? Ihr wirtschaftspolitischer

Einfluß und dessen Effekte im internationalen und intersektoralen

Vergleich

Roland Czada, Regierung und Verwaltung als Organisatoren

gesellschaftlicher Interessen

Hajo Weber, Selbststeuerung der Verbände? 
V. Regieren im Zeichen der Medienherrschaft

Christine Landfried, Die Macht des Fernsehens: Inszenierung statt

Kontrolle von Politik

Otfried Jarren, Politische Kommunikation im elektronischen Zeitalter. Über die Veränderungen von Öffentlichkeit und politischen Prozessen im „Viel-Kanal-Mediensystem“

VI. Regieren - die Kunst rationaler Intervention in historische Verläufe?

Hans-Hermann Hartwich, Die Bundesregierung im Prozeß der deutschen Vereinigung (1989/90). Skizze zu einer kategorial geleiteten Analyse des Regierungshandelns

Dirk Käsler, Charismatische Herrschaft und der charismatische Führer im Werk Max Webers 